\title{
Antibiotic Resistance and Occurrence of Class 1 Integrons in Clinical Isolates of Salmonella enterica
}

Zakharyan, M. K.; Sedrakyan, A. M. ; Arakelova, K. A. ; Hovannisyan, A. I. ; Asoyan, A. V. ; Gevorgyan, Z. U.; Mnatsakanyan, A. A. ; Ktsoyan, Zh. A. ; Boyajyan, A. S. ; Aminov, Rustam

\section{Published in:}

Global Journal of Immunology and Allergic Diseases

Link to article, DOI:

$10.14205 / 2310-6980.2013 .01 .02 .1$

Publication date:

2013

Document Version

Publisher's PDF, also known as Version of record

Link back to DTU Orbit

Citation (APA):

Zakharyan, M. K., Sedrakyan, A. M., Arakelova, K. A., Hovannisyan, A. I., Asoyan, A. V., Gevorgyan, Z. U., Mnatsakanyan, A. A., Ktsoyan, Z. A., Boyajyan, A. S., \& Aminov, R. (2013). Antibiotic Resistance and

Occurrence of Class 1 Integrons in Clinical Isolates of Salmonella enterica. Global Journal of Immunology and Allergic Diseases, 1, 44-48. https://doi.org/10.14205/2310-6980.2013.01.02.1

\section{General rights}

Copyright and moral rights for the publications made accessible in the public portal are retained by the authors and/or other copyright owners and it is a condition of accessing publications that users recognise and abide by the legal requirements associated with these rights.

- Users may download and print one copy of any publication from the public portal for the purpose of private study or research.

- You may not further distribute the material or use it for any profit-making activity or commercial gain

- You may freely distribute the URL identifying the publication in the public portal 


\title{
Antibiotic Resistance and Occurrence of Class 1 Integrons in Clinical Isolates of Salmonella enterica
}

\author{
M.K. Zakharyan ${ }^{1, *}$, A.M. Sedrakyan ${ }^{1}$, K.A. Arakelova1, A.I. Hovannisyan ${ }^{1}$, A.V. Asoyan², \\ Z.U. Gevorgyan², A.A. Mnatsakanyan², Zh.A. Ktsoyan ${ }^{1}$, A.S. Boyajyan ${ }^{1}$ and R.I. Aminov ${ }^{3}$ \\ ${ }^{1}$ Institute of Molecular Biology of National Academy of Sciences of RA, 7 Hasratyan St., 0014, Yerevan, \\ Republic of Armenia \\ 2"Nork" Clinical Hospital of Infectious Diseases, Ministry of Health of Republic of Armenia, 53 Armenakian St., \\ Yerevan, Republic of Armenia \\ ${ }^{3}$ Technical University of Denmark, Copenhagen, Denmark
}

Abstract: Screening of non-typhoidal Salmonella enterica clinical isolates $(n=20)$ by PCR revealed the high prevalence of class 1 integrons (45\%). Multidrug-resistant (MDR) phenotypes were observed in all integron-positive isolates, regardless of the serotype. A significant correlation was found between the MDR phenotype and the presence of class 1 integrons in the isolates, especially in $S$. Typhimurium.

Keywords: Salmonella enterica, class 1 integrons, multidrug resistance.

\section{INTRODUCTION}

Multidrug-resistant (MDR) Salmonella enterica strains are considered as a significant threat to human health in both developed and developing countries. Association between class 1 integrons and MDR has been established for a number of $S$. eneterica serotypes [1-5]. Surveillance and epidemiological studies demonstrated a considerable geographic variation in the prevalence and types of integrons among clinical isolates $[1,2,4,5]$. However, there is a lack of information on the occurrence of class 1 integrons in Salmonella isolates in Armenia. Thus the aim of the present work was to investigate the prevalence of class 1 integrons and their relationship with the susceptibility to antibiotics in non-typhoidal Salmonella clinical isolates at this location.

\section{MATERIALS AND METHODS}

\subsection{Isolates}

The study included a collection of 20 non-typhoidal Salmonella enterica subsp. enterica strains isolated in 2011 from the patients at the "Nork" Clinical Hospital of Infectious Diseases (Yerevan, Armenia). Diagnosis was based on clinical presentations and laboratory analyses. Clinical presentations consistent with gastroenteritis were diarrhea, fever, nausea, vomiting, and abdominal cramps. Anamnesis of food consumed,

*Address correspondence to this author at the Institute of Molecular Biology of National Academy of Sciences of RA, 7 Hasratyan St., 0014, Yerevan, Republic of Armenia; E-mail: linazakharyan@gmail.com water sources, social gatherings, anybody else with a similar illness, and any recent history of travel was also recorded. For this investigation, only the patients that were not taking any type of medication including antibiotics before the hospital admission were chosen. Fecal samples were collected on the first or the second day of hospital admission. All the strains isolated from fecal samples confirmed to be Salmonella enterica by standard biochemical and serological tests. Biochemical tests for the identification of Salmonella were fermentation of glucose, negative urease reaction, lysine decarboxylase, negative indole test, $\mathrm{H}_{2} \mathrm{~S}$ production, and fermentation of galactitol (dulcitol). Serotypes of Salmonella were determined using the standard Kauffman-White scheme with the use of commercially available polyvalent antisera for flagellar $(\mathrm{H})$ and for lipopolysaccharide $(\mathrm{O})$ antigens.

For detoxification and rehydration, all patients were subjected to the standard infusion therapy. Based on the severity of the disease, $86 \%$ were placed on antibiotic therapy: (i) $38 \%$ received intravenous or intramuscular ceftriaxone (50mg/kg/day); (ii) $42 \%$ received peroral ciprofloxacin (0.5-1.0 g/day); and (iii) the rest were on the combination of one of the two drugs and trimethoprim/sulfamethoxazole. All study subjects (or parent/guardian if a child), gave their written consent to give fecal samples for the study. The study protocol was approved by the Ethics Committee of the Institute of Molecular Biology NAS RA (IORG number 0003427, Assurance number FWA00015042, and IRB number 00004079). 


\subsection{Antibiotic (AB) Susceptibility Tests}

The isolates were tested for the susceptibility to eight classes of antibiotics by disc diffusion. Standard disk diffusion method was used according to the guidelines of the Clinical and Laboratory Standards Institute (CLSI) [6]. The disks used (Micromaster Laboratories Pvt. Ltd., INDIA) contained ten antibiotics: streptomycin (S), gentamicin (G), amoxicillin/clavulanic acid $(\mathrm{Au})$, ceftriaxone $(\mathrm{Cx})$, trimethoprim/sulfamethoxazole $(\mathrm{Tm} / \mathrm{S})$, sulfisoxazole $(\mathrm{Su})$, ampicillin $(\mathrm{A})$, chloramphenicol (C), ciprofloxacin (Cp), and tetracycline (T). The isolates were classified as susceptible, intermediately resistant or fully resistant according to the CLSI guidelines [7].

\subsection{Detection of Class 1 Integrons}

Total DNA of isolates for PCR-amplification was prepared with the use of the FastDNA $\circledast$ Kit (Qbiogene,
Inc.), according to the manufacturer's protocols. All strains were tested for the presence of class 1 integrase-specific intl1 gene, variable segment of integrons, and $3{ }^{`}$ - conserved segment. Primers, PCR mix composition and PCR conditions used were as described previously [5]. PCR products were visualized by ethidium bromide staining after gel electrophoresis using $1.2 \%$ agarose.

\section{RESULTS}

Among 20 Salmonella clinical isolates tested nine isolates demonstrated the presence of int/1 (Table 1). PCR-amplification with the set of primers for 3 conserved segment indicated that all int $/ 1^{+}$strains produce the amplicons of the expected size (800bp) and thus were positive for the $33^{\prime}$-conserved segment too. The remaining Salmonella isolates did not generate PCR amplicons with any of the primer sets

Table 1: Presence and Type of Class 1 Integrons, and Resistance Profile of Salmonella Clinical Isolates

\begin{tabular}{|c|c|c|c|c|c|c|}
\hline \multirow[b]{2}{*}{$\begin{array}{l}\text { Isolate } \\
\text { number }\end{array}$} & \multirow{2}{*}{$\begin{array}{l}\text { Salmonella } \\
\text { Serotype }\end{array}$} & \multicolumn{3}{|c|}{$\begin{array}{c}\text { PCR-amplification target } \\
\text { (primers set) }\end{array}$} & \multirow[b]{2}{*}{ Resistance profile } & \multirow[b]{2}{*}{$\begin{array}{c}\text { Number of AM } \\
\text { classes }^{c}\end{array}$} \\
\hline & & $\begin{array}{c}\text { intl1 } \\
(1 U-1 D)\end{array}$ & $\begin{array}{c}V^{a} \\
\text { (inF-inB) } \\
\text { b.p. }\end{array}$ & $\begin{array}{c}3^{\prime}-\mathrm{CS}^{\mathrm{b}} \\
(\text { qacE } \Delta 1-F \\
\text { sul1-B) }\end{array}$ & & \\
\hline 1 & S. Enteritidis & - & - & - & - & 0 \\
\hline 2 & S. Enteritidis & - & - & - & - & 0 \\
\hline 3 & S. Enteritidis & - & - & - & - & 0 \\
\hline 4 & S. Enteritidis & - & - & - & - & 0 \\
\hline 5 & S. Typhimurium & - & - & - & - & 0 \\
\hline 6 & S. Enteritidis & - & - & - & A & 1 \\
\hline 7 & S. Enteritidis & - & - & - & $T^{*}$ & 1 \\
\hline 8 & S. Typhimurium & - & - & - & $\mathrm{AAu}$ & 2 \\
\hline 9 & S. Typhimurium & - & - & - & $\mathrm{AAu}$ & 2 \\
\hline 10 & S. ser. I 4,[5],12:i:- & - & - & - & ASuTm $/ \mathrm{ST}^{*} \mathrm{Cx}$ & 4 \\
\hline 11 & S. Enteritidis & + & 1000 & + & ASSuTm/SAu* & 4 \\
\hline 12 & S. Enteritidis & - & - & - & CpCSGTSuCx & 6 \\
\hline 13 & S. Enteritidis & + & 1000 & + & ACSSuTm/SAuCx ${ }^{*}$ & 6 \\
\hline 14 & S. Enteritidis & + & 1000 & + & ACSSuTm/SAuCx & 6 \\
\hline 15 & other Salmonella & + & 1000 & + & ACSSuTm/SAuCx & 6 \\
\hline 16 & S. Typhimurium & + & 1000 & + & ACSSuTm/STAu* & 6 \\
\hline 17 & S. Typhimurium & + & 1500 & + & ACSSUTm/STAuCx & 7 \\
\hline 18 & S. Typhimurium & + & 1500 & + & ACSSuTm/STAu*Cx & 7 \\
\hline 19 & S. Typhimurium & + & 1500 & + & ACSSuTm/STAu*Cx & 7 \\
\hline 20 & S. Typhimurium & + & 1500 & + & ACSSUTm/STAuCx & 7 \\
\hline
\end{tabular}

${ }^{a}$ variable segment of integron; ${ }^{b} 3$-conserved segment of integron; ${ }^{c}$ number of antimicrobial classes to which the isolate is resistant; ${ }^{*}$ intermediate resistance to the drug. 
used (Table 1) and, therefore, they were considered as integron-negative (int/1).

Thus, the results showed the presence of class 1 integrons in $45 \%$ of the isolates (9 out of 20 ), five of which were identified as $S$. Typhimurium (55.6\%), three isolates were identified as $S$. Enteritidis (33.3\%), and one strain belonged to another Salmonella serotype (Table 1).

PCR-amplification with the set of primers targeting the variable segment of integrons indicated the putative gene cassettes in all int $/ 1^{+}$strains (Table 1, Figure 1) since there were no "empty" integrons among them. All variable segments were represented by a singl? amplicon, and these amplicons were represented by two types: (i) those producing a $1000 \mathrm{bp}$ amplicon (5 isolates: $3-S$. Enteritidis, $1-S$. Typhimurium, and $1-$ other Salmonella), and (ii) those producing an amplicon of about $1500 \mathrm{bp}$ (4 isolates, all $S$. Typhimurium).

All Salmonella clinical isolates were tested for the susceptibility to ten antibiotics. The highest level of susceptibility among the isolates tested was registered towards ciprofloxacin and gentamicin (95\%). Resistance profiles and the number of antibiotic classes to which bacterial isolates were simultaneously resistant are summarized in Table 1. Based on these results, a comparative analysis of $i n t / 1^{+}$and int $11^{-}$ isolates was performed in order to reveal the association of antibiotic resistance phenotypes with integrons.
Five isolates (25\%) were sensitive to all antibiotics tested (Table 1, isolates 1-5). It is noteworthy that all these sensitive isolates were int/1, with the majority belonging to the $S$. Enteritidis serotype (isolates 1-4). Resistance to one or two classes of antibiotics was observed in four isolates $(20 \%)$, and they were also int/1' (isolates 6-9).

The results revealed that $55 \%$ of the isolates tested (11 of 20) were resistant to four or more antibiotics (isolates 10-20) thus displaying an MDR phenotype. Notably, about $82 \%$ of MDR isolates were int $11^{+}$( 9 out of 11) and the MDR phenotypes were observed in all integron-positive isolates, regardless of the serotype. Our study revealed only two int $11^{-}$strains with MDR phenotypes (isolates 10 and 12), and their resistance profiles were markedly different from the profiles of other MDR strains.

Currently, S. Enteritidis and S. Typhimurium are the predominant Salmonella serotypes encountered in clinical isolates in the region. Therefore, it was interesting to consider the MDR phenotype in these serotypes separately.

Five out of eight $S$. Typhimurium isolates tested $(62.5 \%)$ were resistant to at least six classes of antibiotics thus displaying an MDR phenotype (isolates 16-20). Moreover, the isolate 16 exhibited ACSSuT resistance profile, typical of $S$. Typhimurium phage type DT104 [1, 2, 4]. It is known that among the $S$. Typhimurium DT104 strains the genes encoding for the

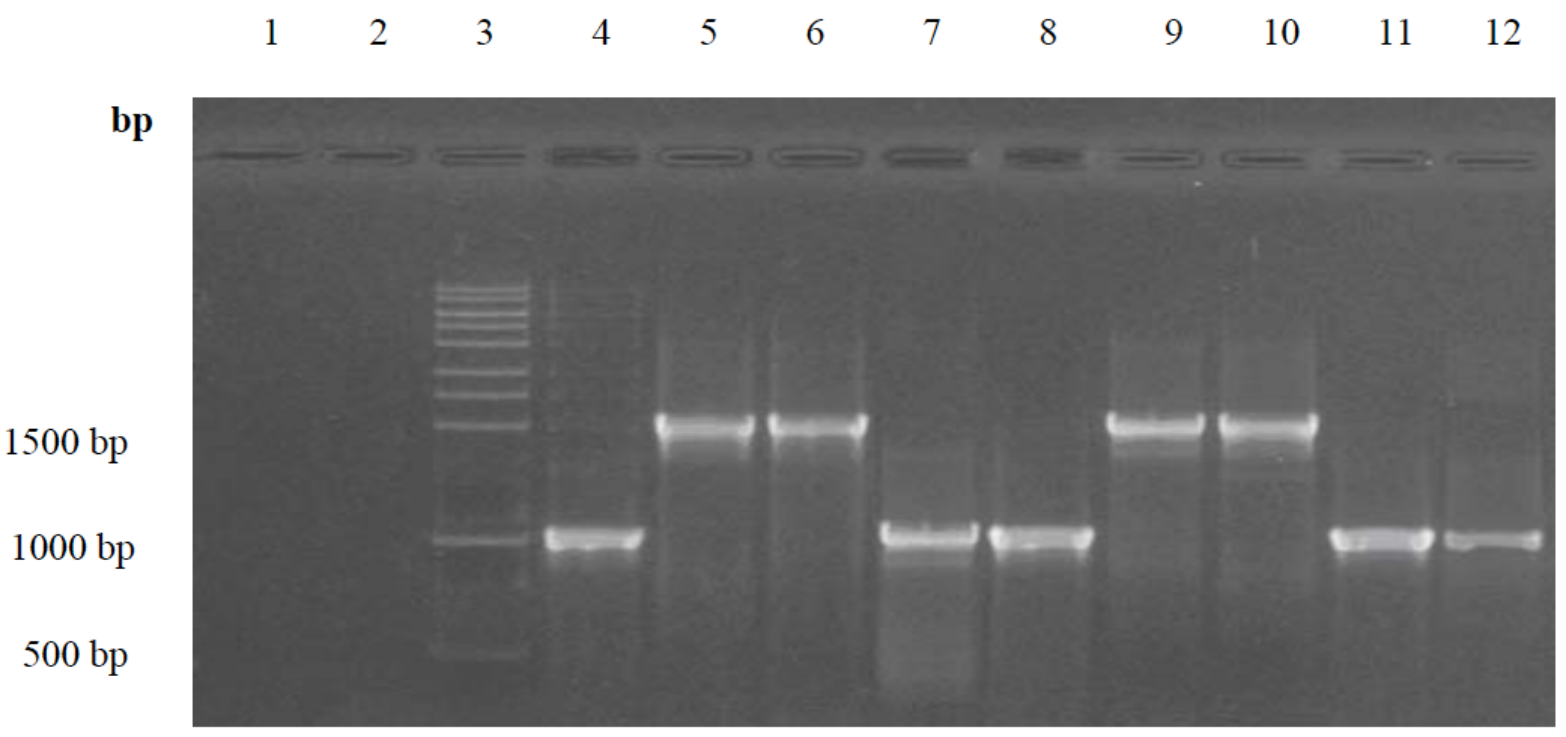

Figure 1: Electrophoretic separation of PCR amplicons generated with the inF-inB primer set (specific for variable segment of class 1 integrons): $1-\mathrm{H}_{2} \mathrm{O}$ control; $2-E$. coli $\mathrm{K} 12$ (negative control), 3 - DNA mol. weight markers (DNA-Leiter kombi, CL 22.1); 4-12 - Salmonella clinical isolates (4, 7, 8 - S. Enteritidis; 5, 6, 9, 10, 11 - S. Typhimurium; 12 - another S. enterica serotype). 
mentioned penta-resistance profile are located in complex class 1 integrons, named In104, within $3^{\prime}$ end of the chromosomal genomic island SGI1 [1, 8]. SGI1 is an integrative mobilizable element (IME), which can be transferred horizontally to other serotypes [9, 10]. The different types of SGI1 MDR complex integrons have been described in a wide variety of $S$. enterica serotypes $[11-13,18]$.

Noticeably, four of the remaining $S$. Typhimurium isolates with the MDR phenotype exhibited the same resistance profile to seven classes of antibiotics, ACSSuTAuCx (isolates 17-20). It is known as another important MDR phenotype of non-typhoidal Salmonella [14]. This profile includes resistance to amoxicillin/clavulanic acid $(\mathrm{Au})$ and ceftriaxone $(\mathrm{Cx})$ in addition to the penta-resistance profile of $S$. Typhimurium phage type DT104.

Conspicuously, all MDR $S$. Typhimurium isolates were int $11^{+}$while the remaining $S$. Typhimurium isolates were resistant to no more than two classes of antibiotics and all of them were int/1 ${ }^{-}$. Thus, the strong association between MDR phenotype and the presence of class 1 integrons in the $S$. Typhimurium isolates was observed.

Among the ten $S$. Enteritidis isolates tested, four $(40 \%)$ were resistant at least to four antibiotic classes thus exhibiting an MDR phenotype. Moreover, three of them (isolates 12-14) exhibited the profiles of resistance to six antibiotic classes, closely resembling the aforementioned penta-resistance profile, typical of S. Typhimurium DT104. The differences were observed in resistance to one antibiotic (Table 1). It is notable that all 3 int $/ 1^{+} S$. Enteritidis isolates were MDR, similarly to int $/ 1^{+} S$. Typhimurium. However, we revealed one $S$. Enteritidis isolate with the MDR phenotype, which was int/1' (isolate 12).

\section{DISCUSSION}

In this work we focused on the prevalence of class 1 integrons and comparative analysis of resistance profiles between integron-positive and integronnegative isolates. Screening of Salmonella clinical isolates $(n=20)$ detected the high prevalence of class 1 integrons (45\%) with the two types of embedded gene cassettes of about 1000 bp (predominantly in $S$. Enteritidis) and 1500 bp (S. Typhimurium only), occurring separately.

Susceptibility testing indicated the high prevalence of MDR phenotypes in Salmonella clinical isolates
(55\%), with the higher percentage of $S$. Typhimurium (62.5\%) compared to $S$. Enteritidis (40\%). Notably, the MDR phenotypes were observed in all integron-positive isolates, regardless of the serotype. Our results revealed the more frequent occurrence of the MDR phenotype in integron-positive isolates compared to integron-negative, especially for $S$. Typhimurium isolates. The results indicated a strong association between the MDR phenotype and the presence of class 1 integrons in the $S$. Typhimurium isolates. Still, not all MDR Salmonella isolates were int $11^{+}$, two of them were found to be intl1. The latter suggests that the repertoire of mobile genetic elements (MGEs) carrying the battery of antibiotic resistance genes in our Salmonella isolates is not limited to integrons but may be represented by other MGEs as well.

In general antibiotic resistance profiles displayed certain serotype-specific features. Our results revealed that $25 \%$ of the isolates tested exhibited MDR phenotypes typical of non-typhoidal Salmonella, either with penta-resistance, ACSSUT, as in S. Typhimurium DT104, or resistance to 7 (ACSSuTAuCx) antibiotics [14]. It is of note that the latter isolates were $S$. Typhimurium, which is of great concern. Notably, among the $S$. Enteritidis isolates tested this MDR phenotype was not detected, although the closely related resistance patterns were observed. Although the resistance level in $S$. Enteritidis isolates is not as high as in S. Typhimurium, the MDR phenotype has become increasingly common in $S$. Enteritidis, which may compromise the therapy.

\section{CONCLUSIONS}

Thus, the results indicated the high prevalence of class 1 integrons and associated MDR among the clinical Salmonella enterica isolates in Armenia, which may complicate the choice of antibiotics for empirical therapy. Further studies are necessary to reveal the genetic background of MDR phenotypes and to estimate the genetic kinship among the isolates. More rigorous regulations should be imposed on antibiotic use, together with a vigilant epidemiological surveillance, to prevent the emergence and spread of MDR non-typhoidal Salmonella isolates.

\section{REFERENCES}

[1] Boyd D, Peters GA, Cloeckaert A, Sidi Boumedine K, Chaslus-Dancla $\mathrm{E}$, Imberechts $\mathrm{H}$, et al. Complete nucleotide sequence of a 43-kilobase genomic island associated with the multidrug resistance region of Salmonella enterica serovar Typhimurium DT104 and its identification in phage 
type DT120 and serovar Agona. J Bacteriol 2001; 183: 57255732.

http://dx.doi.org/10.1128/JB.183.19.5725-5732.2001

[2] Krauland MG, Marsh JW, Paterson DL, Harrison LH. Integron-mediated multidrug resistance in a Global collection of nontyphoidal Salmonella enterica isolates. Emerging Infectious Diseases 2009; 15(3): 388-396. http://dx.doi.org/10.3201/eid1503.081131

[3] Mazel D. Integrons: agents of bacterial evolution. Nature Rev Microbiology 2006; 4: 608-620. http://dx.doi.org/10.1038/nrmicro1462

[4] Vo ATT, van Duijkeren E, Gaastra W, Fluit AC. Antimicrobial Resistance, Class 1 Integrons, and Genomic Island 1 in Salmonella Isolates from Vietnam. PLoS ONE 2010; 5(2): e9440.

[5] Zhang H, Shi L, Li L, Guo S, Zhang X, Yamasaki Sh, et al. Identification and characterization of class 1 integron resistance gene cassettes among Salmonella strains isolated from healthy humans in China. Microbiol Immunol 2004; 48(9): 639-645. http://dx.doi.org/10.1111/j.1348-0421.2004.tb03473.x

[6] National Committee for Clinical Laboratory Standards. Performance standards for antimicrobial disk and dilution susceptibility tests. M31-A2- Approved standard, 2nd ed. NCCLS, Wayne, PA, USA 2001.

[7] CLSI. Performance Standards for Antimicrobial Susceptibility Testing; Twenty-Second Informational Supplement. M100S22. Wayne, PA, USA; 2012.

[8] Mulvey MR, Boyd DA, Olson AB, Doublet B, Cloeckaert A. The genetics of Salmonella genomic island 1. Microbes Infect 2006; 8: 1915-1922. http://dx.doi.org/10.1016/j.micinf.2005.12.028
[9]

Cloeckaert A, Schwarz S. Molecular characterization, spread and evolution of multidrug resistance in Salmonella enterica typhimurium DT104. Vet Res 2001; 32: 301-310. http://dx.doi.org/10.1051/vetres:2001126

[10] Threlfall EJ. Epidemic salmonella typhimurium DT 104-a truly international multiresistant clone. J Antimicrob Chemother 2000; 46: 7-10.

http://dx.doi.org/10.1093/jac/46.1.7

[11] Ahmed AM, Hussein AIA, Shimamoto T. Proteus mirabilis clinical isolate harbouring a new variant of Salmonella genomic island 1 containing the multiple antibiotic resistance region. J Antimicrob Chemother 2007; 59: 184-190. http://dx.doi.org/10.1093/jac/dk/471

[12] Boyd DA, Shi X, Hu QH, Ng LK, Doublet B, Cloeckaert A, et al. Salmonella Genomic Island 1 (SGI1), Variant SGI1-I, and a New Variant SGI1-O in Proteus mirabilis Clinical and Food Isolates from China. Antimicrob Agents Chemother 2008; 52(1): 340-344.

http://dx.doi.org/10.1128/AAC.00902-07

[13] Doublet B, Poirel L, Praud K, Nordmann P, Cloeckaert A. European clinical isolate of Proteus mirabilis harbouring the Salmonella genomic island 1 variant SGI1-O. J Antimicrob Chemother 2010; 65: 2260-2262. http://dx.doi.org/10.1093/jac/dkq283

[14] CDC. National Antimicrobial Resistance Monitoring System for Enteric Bacteria (NARMS): Human Isolates Final Report, 2010. Atlanta, Georgia: U.S. Department of Health and Human Services, CDC, 2012.

Received on 29-11-2013

(C) 2013 Zakharyan et al.; Licensee Pharma Professional Services.

This is an open access article licensed under the terms of the Creative Commons Attribution Non-Commercial License (http://creativecommons.org/licenses/by-nc/3.0/) which permits unrestricted, non-commercial use, distribution and reproduction in any medium, provided the work is properly cited. 